\title{
VERDAD Y CONCEPTO EN LA FILOSOFÍA DE FRIEDRICH NIETZSCHE
}

\author{
Juan José COLOMINA \\ Univesitat de València
}

RESUMEN. Quien escribe pretende con este ensayo sumarse a la larga lista de trabajos que resaltan las inquietudes del filósofo alemán Friedrich Nietzsche sobre el conocimiento. Como es obvio, no existe ningún tipo de pretensión de agotar el tema, ya que no se trata ni la aproximación nietzscheana a la ciencia ni a los demás saberes especulativos, sino que tan sólo pretende delimitar (a grandes rasgos) el modo en que debemos entender los términos Concepto y Verdad dentro del sistema nietzscheano, algo que permitirá una mejor comprensión de la entera obra de Nietzsche. Como también se muestra, las preocupaciones epistemológicas nietzscheanas se fundamentan en un modus vivendi peculiar (de resonancia kierkegaardiana) mucho más cercano al existencialismo helénico que a los desvaríos de un desequilibrado.

Palabras ClaVE. Concepto, Verdad, vida, voluntad (de verdad), voluntad (de poder), espiritu libre, realidad.

\section{La preocupación por el conocimiento}

En una serie de manuscritos dedicados a Cósima Wagner, escribe Nietzsche:

«En algún apartado rincón del universo, derramado centelleante en un sinnúmero de sistemas solares, hubo una vez un astro en el que animales inteligentes inventaron el conocimiento. Fue el minuto más arrogante y mendaz de la 'historia universal', pero, con todo, un minuto tan sólo. Tras haber la Naturaleza alentado unas pocas veces, se congeló el astro, y los animales inteligentes tuvieron que morir. Y fue en buena hora: pues aunque ellos se pavonearan de haber conocido ya muchas cosas, sin embargo, finalmente 
habían acabado por descubrir, para gran decepción suya, que todo habíanlo conocido erróneamente. Murieron y maldijeron la verdad al morir. Tal fue la índole de estos animales desesperados que hubieron inventado el conocimiento", Nietzsche (1999: 21).

Y tras una breve reformulación del parágrafo anterior, dice Nietzsche en Sobre verdad $y$ mentira en sentido extramoral,

«Alguien podría inventar una fábula semejante pero, con todo, no habría ilustrado suficientemente cuán lastimoso, cuán sombrío y caduco, cuán estéril y arbitrario es el estado en el que se presenta el intelecto humano dentro de la naturaleza», Nietzsche (1996: 17).

Estos dos fragmentos recogen en sí el comienzo de lo que serán las preocupaciones de Nietzsche hasta su muerte. Estos escritos del todavía joven catedrático de Filología Clásica de la Universidad de Basilea (ya que están escritos entre 1872 y 1873), muestran las inquietudes que perseguirán a nuestro autor: preocupación por la verdad (por el conocimiento de un mundo inconmensurable que no puede reducirse a conceptos y categorías), atención a la invención que supone ese conocimiento epistemológico, alusión a la limitación humana en el mundo de las fuerzas contrarias, preocupación por un hombre que intenta huir del mundo verdadero (frente al que se encuentra desnudo) mediante un ropaje de conceptos que le permitan cubrirse (formando así la Verdad).

Como bien dice Nietzsche, «en un apartado rincón del universo", en la esquina más oscura de la multiplicidad que en realidad es el mundo, encontramos al hombre. El hombre aparece desnudo, tembloroso, acobardado, frente a una realidad que no reconoce como suya, pero a la que irremediablemente pertenece. Ese mundo real se le presenta como algo amorfo, como algo indeterminado, como una pluralidad que lo desconcierta, que no puede entender, que se le escapa porque no puede contenerlo todo en sí.

El hombre es un animal indefenso ante un devenir, ante un cambio, ante una multiplicidad, que es capaz de captar por medio de los sentidos, pero que se le escapa porque constantemente fluye, constantemente cambia. Esa realidad le muestra una pluralidad de elementos contrarios que impiden una concreción, le muestra multitud de opuestos que no puede asimilar. 
Esa realidad se le muestra como hostil, esa realidad se le escapa por la inmensidad de su pluralidad. El hombre no es capaz de vivir con esa inseguridad del cambio, cambio que le provoca miedo y dolor. El hombre se siente indefenso frente al cambio, el hombre necesita la estabilidad del mundo para poder ser. Porque, en definitiva, lo que quiere el hombre es ser. Y no puede ser si continuamente está cambiando, si continuamente el mundo se confunde con el hombre y el hombre se confunde con el mundo.

Como el resto de animales, el hombre pretende sobrevivir en un mundo que le es hostil, sobrevivir en un mundo que siempre pretende eliminarlo. Pero el hombre no está dotado de garras o cuernos como los demás animales, la Naturaleza lo dotó de un instrumento todavía más mortífero: el intelecto. Este intelecto le permite captar ese devenir, reflexionar sobre la pluralidad, congelar el fluir del cambio, matar el mundo. Matar no sólo al mundo, matarse también a sí mismo, a su vitalidad, a su espontaneidad, matarse a sí como parte del mundo que deviene.

El hombre posee el intelecto, y con él puede crear partiendo del mundo. Si todos los animales quieren sobrevivir, y el hombre es uno más de esos animales (sólo que está indefenso ante el mundo, y es capaz de emplear cualquier estratagema que tenga a mano), el hombre sólo puede construir un mundo que no devenga, un mundo estable, fijo, permanente... que le dé la seguridad suficiente para vivir, para sobrevivir.

Nietzsche comienza desde una duda: si el universo es un infinito y el planeta Tierra tan sólo es un punto dentro de él, ¿por qué debe estar todo hecho para el animal que reina en dicho punto? Si el hombre es sólo una unidad dentro de un universo ilimitado que siempre fluye y cuyos límites no podemos conocer, entonces ¿por qué ese hombre piensa que todo es (y todo el énfasis recae en el ser) a "su imagen y semejanza"? Nietzsche responde ingeniosamente: ese universo infinito, ese devenir en donde nada permanece que es en realidad el mundo da miedo a los animales que son capaces de captar ese devenir. Por ello, necesitan de inmediato sobrevivir a dicho continuo cambio que los confunde y que constantemente los amenaza con absorberlos de tal forma que dejen de ser al confundirse con el todo. Porque, en definitiva, ese es el problema: el hombre necesita ser para poder reinar en ese planeta, pero no es posible hasta que no detenga el devenir que el mundo es. Es entonces cuando comienza la mentira y la "ver- 
dad" se transforma para no volver a cambiar, se transforma para detener ese devenir (se convierte en Verdad).

\section{La deuda con Heráclito}

La concepción de un tal devenir primigenio tiene ascendencias heraclíteas: en Heráclito, el mundo es un constante devenir, es un cambio continuo, por este motivo (al igual que no podemos sumergirnos dos veces en el mismo río) no podemos conocer el mundo tal como realmente es, porque es un continuo devenir. El mundo es un cambio incesante, y esto es lo único real.

Pero antes hemos dicho que el hombre necesita identificar a su "depredador" para poder sobrevivir. Del mismo modo que la gacela tiende a identificar como iguales a sus depredadores (que siempre son desiguales y distintos) para poder salvar su vida, el hombre (como animal superior a todos aquellos que pueblan el mundo) emplea todo su intelecto para igualar la desigualdad y poder, así, hacer que cese el devenir. Cuando identifica como iguales a los objetos del mundo similares entre sí, lo que el hombre hace es salvarse a sí mismo de perecer en ese devenir.

Pero ello no supone una traición, sino una necesidad. Es algo instintivo en el hombre el querer sobrevivir a ese devenir, por lo que necesita crear el soporte lógico y categórico que le permita afirmar el mundo, pero al precio de negar la vida. Ese algo instintivo se identifica con lo que Nietzsche denomina Voluntad de verdad.

El intelecto humano abstrae las características comunes a los objetos materiales similares y forma con ellas las ideas o conceptos de dichos objetos. Esa idea es la representación abstracta de lo que ese objeto es y es ese intento de sobrevivir el que, además, obliga al hombre a dotar de conceptos a la idea para que los hombres puedan comunicarse entre sí. Por medio del concepto, el hombre deja de expresar la espontaneidad y la vitalidad de sus sentimientos, de su corporalidad, aquello que realmente le transmite la cosa; con el concepto el hombre ya no expresa. Con el concepto el hombre tan sólo transmite el sentido, el valor, la verdad... de corte medio que se ha querido significar con dicho término.

Es por ello que Nietzsche afirma que "... la palabra mata, todo lo que está fijo mata" (Nietzsche, 1997a: 69). Podemos extraer dos ideas en esta afirmación. 
Primero, el concepto (que sólo es el significado común que se ha querido dar a una cierta circunstancia del mundo, a una cierta parte de él) mata la espontaneidad del momento, mata la vitalidad del "aquí y ahora" del que tiene la vivencia. El concepto mata la vida. El concepto congela la vitalidad del hombre (vitalidad que le es propia) y la sustituye por un valor de término medio que sólo es una construcción inicial de la que el hombre se sirvió en un principio y de la que ha olvidado que es creador. Ahora, el hombre cree que ese concepto realmente transmite la realidad. El hombre cree que ese sentido establecido es la verdad y que no puede ser de otra forma ${ }^{1}$.

Pero no sólo mata la espontaneidad del momento y la vitalidad del hombre, sino que también (y es lo segundo) mata al mundo. El hombre congela también el devenir, pone límites a lo ilimitado, encierra a lo que no puede ser contenido. El concepto es un símbolo, sólo un símbolo².

El concepto tan sólo es el símbolo que el hombre emplea para denominar a una cierta situación, a una cierta parte del mundo. El concepto es un sentido determinado, congelado, fijo, permanente... que el hombre emplea para comunicar aquello que el mundo le inspira. Sólo existe un problema: si el concepto mata la espontaneidad del mundo, la vitalidad del momento y del «aquí y ahora" del hombre, si el concepto es un significado construido para designar algo establecido, entonces ese concepto es símbolo de la nada porque no designa nada en realidad. El concepto designa una convención, por lo que no existe en realidad. Por tanto, el concepto no sólo mata, sino que además no transmite nada. El concepto es algo vacío, no contiene nada. Pero el hombre olvida esto y lo concibe como verdadero, le otorga autoridad. El hombre cree que el significado del

A este respecto, Nietzsche afirma irónicamente: «[...] Bienaventurados los olvidadizos: pues "digerirán" incluso sus estupideces", Nietzsche (1997b: 174).

2 "A la fusión intimísima y frecuentísima entre una especie de simbolismo de los gestos y el sonido se le da el nombre de lenguaje. En la palabra, la esencia de la cosa es simbolizada por el sonido y por su cadencia, por la fuerza y el ritmo de su sonar, y la representación concomitante, la imagen, la apariencia de la esencia son simbolizadas por el gesto de la boca. Los símbolos pueden y tienen que ser muchas cosas; pero brotan de una manera instintiva y con una regularidad grande y sabia. Un símbolo notado es un concepto: dado que, al retenerlo en la memoria, el sonido se extingue del todo, ocurre que en el concepto queda conservado sólo el símbolo de la representación concomitante. Lo que nosotros podemos designar y distinguir, eso lo 'concebimos'", "La visión dionisíaca del mundo" en Nietzsche (1973: 254). 
hombre designa el mundo como es en sí, por lo que ve en el concepto un reflejo de la realidad. No sólo eso. El concepto aparece como expresión de la esencia del mundo. Si el mundo que vemos está lleno de imperfección y pluralidad, necesariamente la realidad debe situarse en otro lugar. Se crea, así, un mundo inteligible donde existe la realidad, un mundo donde habitan las esencias de las cosas, esencias de las cosas que son fijas, inmóviles, duraderas, únicas, permanentes..., y cuya representación sensible se expresa en el mundo inferior. $Y$ este mundo superior $\mathrm{e}$ inteligible es considerado como la realidad, lo realmente existente que posibilita el resto de las cosas. Y a ese mundo se le denomina Verdadero.

Evitando toda interpretación pragmática en mis palabras, sólo me queda decir al respecto que no es algo meramente útil, sino que (vistas así las cosas) es algo necesario. Como afirma Deleuze, «lo que Nietzsche llama necesidad (destino), no es nunca la abolición sino la combinación del azar mismo. La necesidad se afirma en el azar... Porque existe sólo una combinación del azar como tal,... modo que es como lo uno de lo múltiple» (Deleuze, 1971: 42). El hombre necesita salir de esa angustia que le provoca el devenir, necesita sobrevivir, por ello necesariamente sólo puede disponer del intelecto para evitar ese continuo cambio. Y ese intelecto sólo puede establecer la unidad de aquello múltiple sensible que se le presenta. Por este motivo, la creación de las ideas y de los conceptos es algo que, en principio, responde a una necesidad instintiva, pero cuando se mantienen como la Verdad y pasa al plano no ya de lo biológico, sino al ámbito de la cultura, surge la decadencia del hombre y de su cultura, porque se funda en un error, en una falsedad.

\section{La necesidad de la mentira}

El hombre sólo dispone de un instrumento: el intelecto. El intelecto le posibilita la huída del devenir. Es por esto por lo que el hombre necesita crearse falsos conceptos, falsas categorías, falsas verdades... que fijen un mundo siempre cambiante y, así, poder sobrevivir.

En este momento es cuando podemos afirmar que la "verdad es apariencia. Verdad significa realización del poder, elevación a la mayor potencia. Para Nietzsche, nosotros los artistas = nosotros los buscadores de conocimiento o de verdad = nosotros los inventores de nuevas posibilidades de vida" (Deleuze, 1971: 145). El hombre crea la Verdad, le otorga un sitio en el mundo, le otorga realidad, todo con tal de poder sobrevivir al devenir. 
Pero surge un problema cuando el hombre olvida que es él mismo quien ha creado esos conceptos, esas categorías, esas verdades y las convierte en el mundo real, en lo único existente, en lo único que es.

El hombre olvida que él es quien creó la Verdad, que sólo a él se debe la asociación entre los conceptos y las cosas del mundo, que en realidad los conceptos no expresan el mundo. El hombre ha olvidado su naturaleza creadora y ese recurso originario que tan sólo debía permitir que el hombre sobreviviera acabó convirtiéndose en aquello que ata el hombre al mundo y que ha acabado esclavizándolo. Ahora, el hombre es esclavo de un lenguaje (de conceptos) que ha olvidado que él mismo ha creado y que estructuró el mundo de una determinada manera. Por este mismo motivo, podemos afirmar que «si alguien quiere la verdad no es en nombre de lo que es el mundo, sino en nombre de lo que el mundo no es» (Deleuze, 1971: 136).

\section{Nietzsche afirma}

«En este mismo momento se fija lo que a partir de entonces ha de ser "verdad", es decir, se ha inventado una designación de las cosas uniformemente válida y obligatoria, y el poder legislativo del lenguaje proporciona también las primeras leyes de verdad, pues aquí se origina por primera vez el contraste entre verdad y mentiran, Nietzsche (1996: 20).

Ahora, podemos decir con Nietzsche, las metáforas han dejado de ser aquel instrumento del que el hombre se sirvió en un principio, ese lenguaje originario ha decaído en un lenguaje que expresa mundo, que es estructura antológicamente el mundo. El concepto fue asociado al objeto real que designaba, $y$ ahora ese objeto se subordina al concepto porque se ha olvidado que fue el propio hombre el que los asoció originariamente. Ese lenguaje originario donde una metáfora tan sólo expresaba el mundo, un objeto del mundo, de una determinada manera, ha acabado desgastándose (como la moneda cuyo troquelado se desgasta y pierde todo valor) y acaba muriendo, convirtiéndose así en un concepto que determina cierta parte de la realidad ${ }^{3}$.

3 «Mientras que toda metáfora intuitiva es individual y no tiene otra idéntica y, por tanto, sabe siempre ponerse a salvo de toda clasificación, el gran edificio de los conceptos ostenta la rígida regularidad de un columbarium romano e insufla en la lógica el rigor y la frialdad peculiares de la 
Podemos destacar, con Nietzsche, dos ideas. En primer lugar, el concepto tan sólo es una metáfora que ha perdido todo su valor, es una metáfora muerta e incinerada de la que tan sólo quedan sus cenizas. Pero en Nietzsche no ocurre como en Hegel: de esas cenizas no renace el ave Fénix e inicia de nuevo su vuelo (no se forma ningún nuevo momento histórico a partir de los restos del anterior); en Nietzsche no queda ningún valor. Cuando la metáfora muere, se pierde todo su valor primigenio, toda su necesidad desaparece. Cuando la metáfora se desintegra en cenizas surge el concepto. Pero el concepto no representa nada, es la afirmación de una realidad que ya no existe, afirma el mundo de las ideas (que es inexistente). El concepto queda como una nueva valoración del mundo, una inversión del valor del mundo. Si antes lo bueno era el devenir, el cambio, etc., ahora se reconoce como bueno lo fijo, lo permanente, lo uno, lo idéntico, lo duradero... Y es así como se concibe la realidad, como la Verdad.

En segundo lugar, insistir en el carácter construido de la Verdad y del concepto. La Verdad, por tanto, no es verdadera. El mundo no puede nunca ser expresado conceptualmente porque no puede retenerse el devenir, el devenir tan sólo puede expresarse en el momento. Cuando se congela el devenir en conceptos fijos y eternos, se mata al mundo y se mata la espontaneidad de la realidad.

Pero hemos estado hablando de afirmación, pero afirmación ¿̨de qué? ¿En perjuicio de qué? Decir con Deleuze que uel ser no es objeto de la afirmación, y tampoco el elemento que se ofrecería, se daría como carga a la afirmación. La afirmación no es el poder del ser, al contrario. La propia afirmación es el ser, el ser únicamente es la propia afirmación en todo su poder... El ser y la nada son únicamente la expresión abstracta de la afirmación y de la negación como cualidades de la voluntad de poder", Deleuze, 1971: 259-260). El ser es la afirmación de la vida, el devenir es el ser. Pero el hombre lo olvida y niega la vida para afirmar otra cosa, para afirmar lo fijo, lo estable, lo permanente... la nada.

El hombre posee lo que Nietzsche llama "voluntad de verdad", tiene voluntad de poder, tiene voluntad de dominar. Por este motivo no se conforma con

matemática. Aquel a quien envuelve el hálito de esa frialdad, se resiste a creer que también el concepto óseo y octogonal como un dado y, como tal, versátil, no sea más que el residuo de una metáfora, y que la ilusión de la extrapolación artística de un impulso nervioso en imágenes es, si no la madre, sí sin embargo la abuela de cualquier concepton, Nietzsche (1996: 26-27). 
sobrevivir al devenir. Cuando ha sobrevivido, el hombre desea reinar sobre la Tierra y pasa a dominar al resto de los animales, pasa a dominar a la Naturaleza: el hombre impone los conceptos y obliga a la Naturaleza a situarse por debajo de ellos ${ }^{4}$. El hombre niega la vida, niega los sentidos, niega el ser del devenir, y afirma lo fijo, lo estable, lo inmóvil, lo permanente, lo duradero, lo eterno, lo uno, lo idéntico...; afirma la verdad, el concepto.

Nietzsche afirma

«En prisión.-Mi ojo, por fuerte o débil que sea, únicamente alcanza un tramo determinado, y en ese tramo vivo y existo, esa línea de horizonte es mi más cercano destino, grande o pequeño, al que no puedo sustraerme. En torno a cada ser se cierra un círculo concéntrico semejante que tiene un centro y que le es característico. De modo semejante el oído nos encierra en un pequeńo espacio, y otro tanto ocurre con el tacto. Según estos horizontes, en los que todos nosotros somos recluidos por nuestros sentidos como entre los muros de una prisión, medimos el mundo, llamamos cerca o lejos a esto o aquello: ese medir lo llamamos percibir, ¡no son más que errores, todos ellos errores! Por la cantidad de vivencias y estímulos que nos son posibles por término medio en un instante concreto se mide la vida, breve o larga, pobre o rica, plena o vacía; y por la vida humana promedio se mide eso mismo en todas las demás criaturas, ¡no son más que errores, todos ellos errores!», Nietzsche (1999b: 168).

Podemos extraer dos ideas de este párrafo. Primero, el hombre es un animal activo, necesita sobrevivir al devenir, por ello debe actuar y convertir ese devenir en algo fijo y duradero. Como el resto de predadores, necesita vida para sobrevivir. Como el resto de depredadores, el hombre también posee un instrumento con el que conseguir vida. Ese instrumento es la razón, que dispone de unos ojos en posición frontal que le permiten medir las distancias. El devenir, el cambio,

4 «El problema de los errores que lleva consigo el conocimiento plantea el problema de la verdad de éste. Para Nietzsche, propiamente hablando, no existe la verdad entendida como un conocimiento eterno e inmutable. Esa es una elaboración engañosa del hombre. Éste busca la verdad como un mundo sin contradicciones, sin enganos, sin cambios, un mundo donde no haya dolor. ¿De dónde nace ese mundo? Del desprecio a lo real, a lo que cambia, a lo que se transforma», Suances y Villar (2000: 46). 
es un todo: los ojos del intelecto lo delimitan, lo separan en porciones y las denomina entes. Y a las cosas del mundo las relega a esos entes.

Segundo, esos entes son tomados como la Verdad. El mundo de la apariencia ofrece multiplicidad e inseguridad, el hombre necesita seguridad. Necesita verdades que le muestren el mundo. Necesita de conceptos estables que le permitan dominar el mundo. El intelecto del hombre impone al mundo su yugo, impone al mundo sus categorías, categorías que sólo encarcelan las cosas del mundo, categorías que sólo atrapan y congelan el devenir, que someten al hombre y lo relegan. Los conceptos, las categorías, la Verdad, atan el hombre al mundo. Pero estos entes que catalogan y delimitan el mundo de las cosas y del hombre son algo erróneo. Esta categorización del mundo es falsa, es una construcción del hombre .

El auténtico Ser no es el categorizado, no es el concepto. El único ser es el cambio, el devenir hace el ser, el devenir es el ser. Lo que deviene es, pero nunca es lo mismo; es lo siempre distinto, del laberinto se puede salir de muchas maneras y todas ellas son válidas, el ser es lo que nunca puede ser idéntico. Dice Nietzsche,

"Nosotros hemos descubierto la felicidad, nosotros sabemos el camino, nosotros encontramos la salida de milenios enteros de laberinto. ¿Qué otro lo ha encontrado? - ¿Acaso el hombre moderno?», Nietzsche, (1997a: 31).

En primer lugar, el ser aparece como una huida, un incesante ir y venir de contradicciones, de fuerzas. El ser es el devenir. El devenir que se escapa en lo definido, el cambio que no se puede captar todo a la vez, la salida del laberinto que sólo el Minotauro es capaz de concebir en sí de una sola vez. Porque el conocer la salida del laberinto implica conocer todos los corredores como si fueran la palma de tu mano, y para ello se necesita nacer y vivir en el laberinto, en el devenir. Y, como afirma Nietzsche, esto sólo puede hacerlo un tipo especial de hombre, capaz de ser instintivo, y siéndolo, ser capaz de crear ${ }^{6}$.

5 "El laberinto es lo que nos conduce al ser, no hay más que ser que el del devenir, no hay más ser que el del propio laberinto", Deleuze (1971: 263).

${ }^{6}$ Para vivir sólo hay que ser un animal o un dios- dice Aristóteles. Falta el tercer caso: hay que ser ambas cosas- un filósofo...", Nietzsche (1998a: 33). 
Afirmar también, y es lo segundo, la decadencia del hombre moderno, afirmar el nihilismo de la época moderna. La cultura se contamina del error, de la decadencia, porque se nutre de la Verdad conceptual. Esta Verdad no sólo niega la vida, también imposibilita que nazca una nueva cultura vital, e impide con falsos valores la proliferación de valores de vida.

\section{El mal (endémico) de la modernidad}

Dice Nietzsche,

"Pero entonces ocurríb algo que hizo callar todas las bocas y quedar fijos todos los ojos. Entretanto, en efecto, el volatinero había comenzado su tarea: había salido de una pequeña puerta y caminaba sobre la cuerda, la cual estaba tendida entre dos torres, colgando sobre el mercado y el pueblo. Mas cuando se encontraba justo a la mitad de su camino, la pequeña puerta volvió a abrirse y un compañero de oficio vestido de muchos colores, igual que un bufón, saltó fuera y marchó con rápidos pasos detrás del primero. "Sigue adelante, cojitranco, gritó su terrible voz, sigue adelante, jholgazán, impostor, cara de tísico! ¡Qué no te haga yo cosquillas con mi talón! ¿Qué haces aquí entre torres? Dentro de la torre está tu sitio en ella se te debería encerrar, jcierras el camino a uno mejor que tu!n- - Y a cada palabra se le acercaba más y más: y cuando estaba ya a un solo paso detrás de él ocurrió aquella cosa horrible que hizo callar todas las bocas y quedar fijos todos los ojos: - lanzó un grito como si fuese un demonio y saltó por encima de quien le obstaculizaba el camino. Mas éste, cuando vio que su rival lo vencía, perdió la cabeza y el equilibrio; arrojó su balancín y, más rápido que éste, se precipitó hacia abajo como un remolino de brazos y de piernas. El mercado y el pueblo parecían el mar cuando la tempestad avanza: todos huyeron apartándose y atropellándose, sobre todo allí donde el cuerpo tenía que estrellarse.

Zaratustra, en cambio, permaneció inmóvil, y justo a su lado cayó el cuerpo, maltrecho y quebrantado, pero no muerto todavía. Al poco tiempo el destrozado recobró la conciencia y vio a Zaratustra arrodillarse junto a él. ¿Qué haces aquí, dijo por fin, desde hace mucho sabía yo que el diablo me echaría la zancadilla. Ahora me arrastra al infierno: ¿quieres tú impedírselo?'”, Nietzsche (1998b: 42-43). 
En este fragmento se encuentra, según mi parecer, la mejor descripción del hombre moderno, la mejor descripción de lo que Heidegger denominará sentido de término medio del ser.

El hombre moderno es un hombre que se mueve en un espacio ilimitado, en un espacio que se suspende por encima de las cosas, que no encuentra nada que lo contenga, todo lo desborda. Pero ese espacio es inestable, como lo es la cuerda. El hombre quiere dominar el mundo mediante su Verdad, lo que él considera la "verdad». Para eso necesita detener el devenir del mundo, devenir que provoca miedo al hombre, que pone cara de tísico al hombre. El devenir lo detiene mediante la imposición de categorías que encierran el devenir. $Y$ esas categorías se imponen al mundo. El hombre tiende a imponer su Verdad movido por su voluntad de poder.

Por ese motivo, desequilibra a sus competidores, los expulsa del mundo verdadero, los hace caer bajo su dominio, les hace permanecer sometidos bajo su realidad (realidad que deben aceptar), ya que el mismo lenguaje que se aprende (y que el hombre necesita para ser aceptado como miembro competente de una sociedad) incluye los conceptos y las categorías que estructuran el mundo de una determinada manera. Pero esa Verdad nunca puede ser verdadera porque es una invención del hombre.

Pero Nietzsche no pretende destruir todo el sistema filosófico, todo el sistema social, todo el sistema de valores, de las sociedades modernas. La modernidad es tan sólo el síntoma de un error inicial que se fue agravando con el paso del tiempo. En un comienzo, el hombre vivía con el devenir, en el cambio, en el ir y venir de las cosas nunca idénticas... Pero llegó un momento en el que necesitó de un conocimiento cierto, seguro, único, duradero, fijo, estable... que le permitiera la huída de la angustia y el dolor que el incesante cambio le provocaba. Pero esto no se debe más que a la naturaleza del hombre, naturaleza de los que algunos se aprovecharon ${ }^{7}$.

7 «Llegados a este punto, Nietzsche aclara que la vida es esencialmente voluntad de poder, de afirmación, cuyo espectro va desde las pasiones más rudas hasta el sentimiento estético. Todo es voluntad de poder. Si miramos tanto al mundo como a nuestro interior, veremos que en todas partes laten fuerzas de expansión cuyo resorte se nos escapa. Las plantas y los animales crecen, se reproducen y luchan; allí donde están, ejercen una esfera de dominio. La voluntad de poder se muestra 
Ese devenir que fluye no permite al hombre ser, permanecer; pero el hombre necesita ser. El hombre tiene pretensión de dominar a la Naturaleza, de dominar a ese devenir, de dominar a los demás, por ello necesita construir categorías que retengan el mundo, que constituyan conceptos de algo inmóvil, permanente, fijo... que es la realidad. Pero esa realidad ya no puede pertenecer al mundo sensible, ya que el mundo sensible no les muestra unidad, cohesión, estabilidad... sino multiplicidad. Por este motivo, el hombre crea toda una serie de conceptos que permiten englobar en sí las características comunes de las cosas similares y hacer con ellas una sola cosa: la esencia de las cosas.

Esos conceptos pasan a denominar el mundo, esos conceptos conforman la realidad, la realidad son esos conceptos. Lo sensible no puede ser real porque no permanece, $y$ lo que no permanece es inestable y no puede ser la Verdad. Lo verdadero es sólo aquello fijo, permanente, uno, duradero... que permite conocer el mundo real de una vez por todas. Y esto sólo puede hacerlo la esencia.

Las cosas materiales y múltiples que pueblan el mundo sensible son la representación de una idea, de un modelo perfecto (que es lo real) que les dota de existencia. Pero esa esencia debe existir en un mundo fijo y estable que no devenga, en un mundo que muestre unidad, por lo que debe ser un mundo distinto al sensible. Se crea así el mundo inteligible, un mundo perfecto superior donde existen y están las esencias de las cosas sensibles. Y por debajo de él está el mundo sensible, que es imperfecto.

La voluntad de poder, la voluntad de verdad, la voluntad instintiva en el hombre de dominar a la Naturaleza y de someter a los demás, lo conduce a escindir el mundo. El hombre afirma, por este motivo, la falsa verdad, el concepto vacío, la nada, como el fundamento de todo, como la base sobre la que se construye la nueva vida, como la realidad. Crea, así, un mundo doble: por

aquí en forma de pasiones. Pero también ésta se manifiesta en nuestros procesos psicológicos; éstos son resoluciones de fuerza que se imponen en un determinado momento. Una decisión es una orden repentina de fuerza y de poder; poco tiene que hacer aquí la indiferente deliberación racional. El hombre se guía por un sentimiento de poder. Y hasta el intelecto mismo es un aliado de aquél. Nuestras relaciones amorosas y altruistas son una comunicación de la propia fuerza a los demás; hacemos partícipes a éstos de lo que interesa a nuestros instintos», Suances y Villar (2000: 68). 
una parte, un mundo sensible, bajo, burdo, inferior... que muestra heterogeneidad y pluralidad, y éste no puede ser la verdad porque no se identifica con el ideal; pero por otra parte, se construye un mundo superior, perfecto, inteligible, donde todo es uno, todo permanece estable, todo es, y que pasa a ser el fundamento de toda la realidad. Ese mundo superior pasa a considerarse como la Verdad.

En un principio, el mundo griego todavía es heredero del devenir, la cultura griega contiene en sí la expresión del cambio, de la dialéctica heracliteana (de la verdad heraclítea), contiene en sí la expresión de la contradicción, del choque de fuerzas opuestas, del crear y del destruir. Este devenir, esta idea originaria todavía se expresa en la tragedia griega. La tragedia contiene en sí, todavía, la expresión del creador, la expresión del que constantemente cambia para ser (lo que Nietzsche llama instinto dionisiaco); pero también incluye el instinto apolíneo, el instinto de aquel que aglutina, que escapa al cambio, del que permanece, del que obedece a lo establecido para ser. La conjunción de estos dos instintos originarios es expresión de la auténtica vida, del devenir, y todavía se expresan en la tragedia griega. Se expresa en Penélope cuando por el día se dedica a tejer el manto (ansía cambiar) pero por la noche deshace todo lo avanzado por el día porque desea permanecer en la esperanza, desea quedarse tal como está. Se expresa en Antígona cuando se encuentra en pleno dilema, cuando debe obedecer a las leyes de la familia enterrando a su padre y al mismo tiempo obedecer las leyes de la ciudad no haciéndolo ${ }^{8}$.

Pero ese carácter trágico, constantemente variable, inestable, que se mueve entre mundos, que conjuga fuerzas opuestas y complementarias, angustia al hombre. El hombre se encuentra indefenso frente a ese no saber nunca que será, por lo que inventa el conocimiento. El conocimiento permite al hombre estabilizar-

8 "Con sus dos divinidades artísticas, Apolo y Dionisio, se enlaza nuestro conocimiento de que en el mundo griego subsiste una antítesis enorme, en cuanto a origen y metas, entre el arte del escultor, arte apolíneo, y el arte no-escultórico de la música, que es el arte de Dionisio: esos dos instintos tan diferentes marchan uno al lado de otro, casi siempre en abierta discordia entre sí y excitándose mutuamente a dar luz frutos nuevos y cada vez más vigorosos, para perpetuar en ellos la lucha de aquella antítesis, sobre la cual sólo en apariencia tiende un puente la común palabra "arte": hasta que, finalmente, por un milagroso acto metafísico de la "voluntad" helénica, se muestran apareados entre sí, y en ese apareamiento acaban engendrando la obra de arte a la vez dionisíaca y apolínea de la tragedia ática», Nietzsche (1973: 40-41). 
se, apaciguar sus fuerzas instintivas, matar la vida. A cambio, constituye un andamiaje conceptual, categórico, eidético... que posibilita un dominio del mundo sensible. Se crea entonces la Filosofía para dotar a ese conocimiento de la autoridad de la razón. Se crea el Ser, los entes de las cosas, el mundo inteligible que domina al sensible: se mata así a la vida.

Y el máximo exponente de esta traición a la vida es Platón. El platonismo recoge el socratismo. Es el platonismo el que escinde el mundo: el platonismo eleva la Idea a las alturas, la dota de divinidad, de realidad, de autoridad. No sólo eleva a las alturas a la Idea, sino que relega a la falsedad al mundo sensible. Es el origen de una mentira que perdurará hasta Nietzsche, o eso creía él.

Pero es con la llegada del cristianismo cuando se agudiza la crisis. La decadencia es imparable. La falsa Verdad se transforma en divinidad, en creador, en la realidad extramundana, por lo que aparece la creencia que afirma que la vida se debe a la divinidad: nace Dios. Y esa nueva Verdad que fundamenta toda verdad inteligible también está vacía, es un constructo, es expresión de la nada ${ }^{9}$, por tanto, es falsa. Pero los hombres ascéticos, los sacerdotes, los débiles... imponen esa nueva Verdad, que ya no sólo supone una designación del mundo: ahora también designa una nueva valoración.

El sacerdote envilece el mundo. Por medio del instinto de venganza, invierte todos los valores nobles y los convierte en valores malos, falsos, corruptos... a favor de los valores del débil. Ahora lo que antes era malo y perverso se convierte en lo bueno, lo enfermo y lo débil se convierte en lo bueno porque el hombre no aspira ya a la felicidad mundana y sensible, sino a la felicidad eterna junto a Dios (y esto es la máxima expresión del cuidado de sí que Foucault acaba concluyendo en Hermenéutica del sujeto). Y esto, según Nietzsche, se debe a que "fue justo el sentimiento menos evangélico de todos, la venganza, el que de nuevo se impuso", Nietzsche (1997a: 79).

9 "Cuando se coloca el centro de gravedad de la vida no en la vida, sino en el "más allá" -en la nada,- se le ha quitado a la vida como tal el centro de gravedad. La gran mentira de la inmortalidad personal destruye toda razón, toda naturaleza existente en el instinto, - a partir de ese momento todo lo que en los instintos es beneficioso, favorecedor de la vida, garantizador del futuro, suscita desconfianza. Vivir de tal modo que ya no tenga sentido vivir, eso es lo que ahora se convierte en el "sentido" de la vida», Nietzsche, (1997a: 82-3). 
El sacerdote, movido por un instinto de venganza, impone su Verdad, crea una nueva valoración. Movido por todos los siglos en los que el débil sufría porque no podía superar a los nobles, el sacerdote (el hombre débil) invierte los valores anteriores y convierte lo que antes era malo en bueno; no sólo lo invierte, sino que lo institucionaliza como religión: el cristianismo. $Y$ toda valoración, toda creencia, implica una nueva forma de conducta, un nuevo estado del hombre en el mundo y una nueva manera de afrontarlo. Esta nueva forma de vida ascética niega la vida, supone un abandono de la mundanidad, supone una hostilidad a la vida en favor de una exaltación de la nada, de Dios. Y a esto, el sacerdote lo llama moral ${ }^{10}$.

Pero el sacerdote no se conforma con vengarse, también quiere dominar, quiere reinar sobre el resto de los hombres; también tiene voluntad de poder y sólo dispone de un carácter débil, por lo que sólo puede imponerse mediante el engano y la anulación de la vida, mediante la inversión de los valores. Pero eso impone la moral, porque para reinar necesita que el hombre viva atormentado por la vida mundana, debe procurar que el hombre no viva, que simplemente esté en este mundo sensible (que para él será el único) esperando la salvación y la felicidad de la otra vida. Y para ello debe seguir la moral, debe creerse la Verdad, debe obedecer al sacerdote ${ }^{11}$.

Nietzsche condensa muy bien todas estas cuestiones en un parágrafo de Ecce homo que dice

«... una nueva verdad se hace visible entre espesas nubes. - La verdad del primer tratado es la psicología del cristianismo: el nacimiento del cristianis-

10 «Esta única moral enseñada hasta ahora, la moral de la renuncia a símismo, delata una voluntad de final, niega en su último fundamento la vida. - Aqui quedaría abierta la posibilidad de que estuviese degenerada no la humanidad, sino sólo aquella especie parasitaria de hombre, la del sacerdote, que con la moral se ha elevado a sí mismo fraudulentamente a la categoría de determinador del valor de la humanidad, especie de hombre que vio en la moral cristiana su medio para llegar al poder... Y de hecho, ésta es mi visión: los maestros, los gufas de la humanidad, todos ellos teólogos, fueron todos ellos también décadents: de aquí la transvaloracióm de todos los valores en algo hostil a la vida, de aquí la moral... Definición de la moral: moral -la idiosincrasia de décadents, con la intención oculta de vengarse de la vida-y con éxito. Doy mucho valor a esta definición.-"), Nietzsche (1971: 130-131).

11 "... el sacerdote vive de los pecados, tiene necesidad de que la gente "peque"... Artículo supremo: "Dios perdona a quien hace penitencia"- dicho claramente: a quien se somete al sacerdote.-", Nietzsche (1971: 62). 
mo del espíritu del resentimiento, no del "espíritu", como de ordinario se cree, - un antimovimiento por su esencia, la gran rebelión contra el dominio de los valores nobles. El segundo tratado ofrece la psicología de la conciencia: ésta no es, como se cree de ordinario, "la voz de Dios en el hombre", -es el instinto de la crueldad, que revierte hacia atrás cuando ya no puede seguir desahogándose hacia fuera. La crueldad [...] con la que no puede dejar de contar. El tercer tratado da respuesta a la pregunta de dónde procede el enorme poder del ideal ascético, del ideal sacerdotal, a pesar de ser [...] un ideal de décadence. Respuesta: no porque Dios esté actuando detrás de los sacerdotes, como se cree de ordinario, sino faute de mieux [a falta de algo mejor], - porque ha sido hasta ahora el único ideal, porque no ha tenido ningún competidor. 'Pues el hombre prefiere querer incluso a la nada a no querer'...", Nietzsche (1971: 109-110).

Me gustaría resaltar con Nietzsche tres ideas.

Primera, la inversión de los valores la realiza el sacerdote movido por la cobardía, por la vileza, por el resentimiento, por un instinto de venganza.

Segunda, el resultado de esa inversión es la creación de la conciencia moral: el hombre acaba creyéndose deudor de su creador. Esto es resultado de una moral impuesta no por bondad, sino por crueldad, por la voluntad de poder y de dominio del sacerdote, por su venganza.

Tercera, esta vida es considerada como la única correcta, esta conducta ante el mundo, que es la moral, se toma como ideal. Pero en realidad es un ideal de decadencia porque niega la espontaneidad, niega el cambio, mata a la vida. Es un ideal decadente que funda una cultura nihilista y débil que expandirá el error y no la verdad porque cree en una ficción, en la nada, en la vaciedad de unas categorías y unos valores construidos por el resentimiento que no son los que pertenecen a la naturaleza del hombre.

Esa decadencia toma su máxima expresión con el Idealismo.

Con Kant y Hegel, la realidad ya no se funda en un Dios, sino en la Razón: se diviniza la Razón. La Razón es ahora la que marca la Verdad. 
Con el Idealismo, la Razón ocupa el lugar de la vida. Es la Razón la que posibilita que el hombre sea, que el hombre se desenvuelva en el mundo. La realidad es lo racional. Lo sensible decae frente a la Razón. Todo lo que es real no puede ser nunca plural, tiene que ser homogéneo, uno, fijo, estable... Pero como dice Nietzsche, «Parménides había dicho: 'No se puede pensar lo que no es'; nosotros estamos en el otro extremo y decimos: 'Lo que es pensado debe ser seguramente una ficción'”, Nietzsche (1998c: 302).

Al igual que el sacerdote, el idealista fabrica la Verdad ${ }^{12}$. La verdad de las ideas se funda en la nada. El concepto no es lo real, es algo construido que niega la vida, que impone una realidad falsa en detrimento de los sentidos.

El idealismo ve en el devenir del mundo lo falso, es lo que permanece lo que es verdadero ${ }^{13}$. Los conceptos, las categorías, la Verdad, no pueden proceder de lo sensible porque no permanece, expresa pluralidad y desorden. Los conceptos deben tener una realidad superior donde permanezcan inmutables, y esa realidad es el mundo inteligible, la Verdad.

Pero esos conceptos se extraen de la dialéctica del devenir del mundo sensible, se extraen del cambio, de las contradicciones del mundo, del choque de fuerzas. Sólo que "... toda dialéctica opera y se mueve en el elemento de la ficción. [...] la dialéctica desconoce el sentido, porque ignora la naturaleza de las fuerzas que se apropian concretamente de los fenómenos; desconoce la esencia, porque ignora el elemento real del que derivan las fuerzas, sus cualidades y sus relacio-

12 «Matan, rellenan de paja, esos señores idólatras de los conceptos, cuando adoran, —se vuelven mortalmente peligrosos para todo, cuando adoran. La muerte, el cambio, la vejez, así como la procreación y el crecimiento son para ellos objeciones, -incluso refutaciones. Los que es no deviene; lo que deviene no es... Ahora bien, todos ellos creen, incluso con desesperación, en lo que es. Mas como no pueden apoderarse de ello, buscan razones de por qué se les retiene. "Tiene que haber una ilusión, un engano en el hecho de que no percibamos lo que es: ¿dónde se esconde el engañador?- Lo tenemos, gritan dichosos, ¡es la sensibilidad!». Estos sentidos, que también en otros son tan inmorales, nos engañan acerca del mundo verdadero. Moraleja: deshacerse del engaño de los sentidos, del devenir, de la historia [Historie], de la mentira, -la historia no es más que fe en los sentidos, fe en la mentira", Nietzsche (1998a: 51-52).

${ }^{13}$ "... las categorías de la razón: ellos sacaron la conclusión de que esas categorías no podían proceder de la empiría, - la empiría entera, decían, está, en efecto, en contradicción con ellas", Nietzsche (1998a: 55). 
nes; desconoce el cambio y la transformación, porque se contenta con operar permutaciones entre términos abstractos e irreales», Deleuze (1971: 222). El concepto mata la vida, mata la espontaneidad del choque de las fuerzas contrarias del mundo, mata las contradicciones que son el mundo, el cambio y el devenir que el mundo es.

Por ello, el hombre del Idealismo necesita de esa Verdad, el hombre del Idealismo es la culminación de la función camufladora de los débiles, de los enfermos. El hombre débil necesita camuflar la vida, la verdad del cambio, el devenir, bajo un tupido velo, bajo el camuflaje de la moral, del imperativo categórico, de las normas trascendentales de la Razón. La verdad del mundo queda camuflada bajo el nombre de unidad, eternidad, homogeneidad, concepto, categoría, Verdad. Y este es, por ejemplo, el caso de la cultura alemana, del Idealismo, como último escalón de esa decadencia de los valores nobles, de los valores de la vida ${ }^{14}$.

La moral es extensión de esa falsa realidad, es la expresión de la venganza, del resentimiento en el mundo. La moral no sólo depende de la moral creada por las categorías y los conceptos, no sólo depende del conocimiento, sino que además obliga a que el hombre dependa de él. Si el mundo verdadero se funda en conceptos, en un conocimiento fijo, permanente, de las esencias de las cosas, entonces todo cuanto el hombre haga debe estar encaminado hacia la perfección de esas ideas. Si el mundo verdadero es ideal, entonces también su conducta debe ser ideal. Si el mundo verdadero es uno, permanente y duradero, también el modo de hacerle frente debe serlo, ya que si sólo hay un mundo homogéneo, sólo hay una manera correcta de enfrentarse con él, y esa forma es la que expresa el mandamiento, la ley, la norma moral. Y esa ley y esa norma se impone a la cultura, crea su propia cultura: la cultura del decadente, del resentido. Y el hombre debe seguir esa conducta moral si quiere ser aceptado por esa cultura, por esa

14 "Los alemanes se hallan inscritos en la historia del conocimiento sólo con nombres ambiguos, no han producido nunca más que falsarios «inconscientes» (-Fichte, Schelling, Schopenhauer, Hegel, Scheleiermacher merecen esa palabra, lo mismo que Kant y Leibniz; todos ellos son meros fabricantes de velos [Schleiermacher]-): no van a tener nunca el honor de que el primer espíritu recto en la historia del espíritu, el espíritu en el que la verdad viene a juzgar a los falsarios cuatro siglos, sea incluido entre los representantes del espíritu alemán». Ecce homo, edición citada, p. 119. 
sociedad, el hombre debe seguir la Ley si quiere ser (reconocido como hombre competente que puede ser miembro de una sociedad) ${ }^{15}$.

Pero esa moral, esa Ley, no sólo obligó al hombre imponiéndose como único modo de afrontar correctamente un mundo sensible (que es falso) en espera de llegar al mundo inteligible, el mundo verdadero. Esa moral de esclavos también trastocó la Historia a favor de su mentira, de su Verdad ${ }^{16}$.

El hombre decadente, débil, enfermo, el hombre que crea la Verdad desde la ficción y la nada, que crea la moral desde la venganza y el resentimiento, también inventa una nueva historia con la que obligar al hombre porque, como dice Nietzsche,

«Entonces, el hombre dice: «me acuerdo» y envidia al animal que inmediatamente olvida y ve cada instante morir verdaderamente, hundirse de nuevo en la niebla y en la noche y desaparecer para siempre. Vive así el animal en modo no-historico, pues se funde en el presente como número que no deja sobrante ninguna extraña fracción; no sabe disimular, no oculta nada, se muestra en cada momento totalmente como es $y$, por eso, es necesariamente sincero. El hombre, en cambio, ha de bregar con la carga cada vez más y más aplastante del pasado, carga que lo abate o lo doblega y obstaculiza su

15 "No caminarás a cuatro patas; ésa es la Ley.

¿Acaso no somos hombres?

No sorberás la bebida; ésa es la Ley.

¿Acaso no somos hombres?

No comerás carne ni pescado; ésa es la Ley.

¿Acaso no somos hombres?

No cazarás a otros Hombres; ésa es la Ley.

¿Acaso no somos hombres?"

(H. G. Wells, La isla del Dr. Moreau, capítulo 12).

${ }_{16}$ "Y una vez más, el instinto sacerdotal del judío perpetró idéntico gran crimen contra la historia, - borró sencillamente el ayer, el antesdeayer del cristianismo, se inventó una historia del cristianismo primitivo. Aún más: falsificó otra vez la historia de Israel, para que apareciese como la prehistoria de su acción: todos los profetas han hablado de su "redentor"... Más tarde la Iglesia falseó incluso la historia de la humanidad, convirtiéndola en prehistoria del cristianismo... El tipo del redentor, la doctrina, la práctica, la muerte, el sentido de la muerte, incluso el después de la muerte —nada quedó intacto, nada continuó siendo siquiera parecido a la realidad", Nietzsche (1997a: 81-82). 
marcha como invisible y oscuro fardo que él puede alguna vez hacer ostentación de negar y que, en el trato con sus semejantes, con gusto niega: para provocar su envidia», Nietzsche (2000: 36-7).

El hombre es un animal histórico. El Hombre se cree deudor de un pasado que acepta sin más como suyo. No se da cuenta que esa historia es falsa y que se ha fundado en la mentira, en el resentimiento, en la venganza. Por eso, el hombre decadente necesita falsar su pasado, necesita falsar su historia, necesita maquillar su naturaleza, ocultar el devenir, la vida y el mundo, para poder seguir siendo, para Ser.

Por este motivo, Nietzsche destaca la necesidad imperiosa en el hombre de una genealogía. El hombre moderno es decadente porque se ha basado en una Verdad falsa, en unos valores de resentimiento, en una cultura enferma y débil. Y todo ello sustentado bajo la falsación de la historia y la ocultación del devenir y el verdadero mundo bajo el velo de la unidad, de la permanencia, de la igualdad, de la identidad, de la duración, de los conceptos, de la Verdad.

Es por esto que el hombre nuevo, el espiritu libre, al que Nietzsche llama superhombre, que surge de admitir esta falsedad del mundo inteligible de los conceptos, de su valoración, de su Verdad, necesita desenmascarar la verdad, necesita desvelar lo que se oculta tras los conceptos y el conocimiento, necesita bucear en la historia y descubrir su verdadera cara, su naturaleza, descubrir el mundo tal como éste es, con su devenir, con su cambio, con su contradicción, con su confrontación de fuerzas, con su nunca idéntico ${ }^{17}$.

La realidad, el cambio, la vida, se ocultan tras la Verdad. Esta Verdad necesita ponerse una máscara para poder ser aceptada. Si el mundo sensible es el único, y el hombre no puede aceptarlo porque se le escapa, le da miedo, lo atormenta, pero pretende dominarlo mediante el conocimiento cierto y seguro del mundo, entonces el hombre necesita ocultar esa verdad del mundo que deviene debajo del velo de la unidad, de la identidad, de la permanencia, de la duración... Necesita ocultar el mundo debajo de la máscara de la Verdad. Y esta Verdad se

17 "Lo que en el título se denomina idolo es sencillamente lo que hasta ahora fue llamado ver.dad. Crepuisculo de los idolos, dicho claramente: la vieja verdad se acerca a su final...". Ecce bomo, edición citada, p. 111. 
diviniza, se exalta como real, como lo único existente. Se le dota de existencia superior, se le dota de perfección, se le fabrica un mundo propio; pero por eso mismo esa Verdad es falsa. Por este motivo, Nietzsche ve necesario desenmascarar la Verdad para que muestre su verdadera naturaleza, su mentira, su construcción, su falsedad... y, así, desvelar el devenir, la realidad tal cual, el auténtico mundo ${ }^{18}$.

La Verdad es una invención, una falsedad, una mentira, que se impone al hombre y que oculta debajo de sí la auténtica realidad. Por eso, el hombre se encuentra en decadencia, la cultura es decadente, porque acepta como Verdad esa mentira. Y esa Verdad es la máscara que oculta en sí la verdadera realidad, el instinto de venganza del hombre débil, la voluntad de resentimiento del hombre enfermo, la voluntad de poder del hombre. La Verdad se oculta debajo del velo de la unidad, de la permanencia, de la duración..., debajo de esa máscara se encuentra la multiplicidad, el cambio, el devenir, el mundo real.

Por este motivo, el espiritu libre debe ser el guía que permita al hombre salir de la decadencia, de ser aquel que abra los ojos y vea la falsedad del mundo, debe eliminar la falsa valoración de la moral cristiana, la falsa cultura obtenida de esa moral, debe ser aquel que permita al hombre desvelar la Verdad. Pero su tarea no queda ahí: cuando el hombre haya sido capaz de ser libre, debe retornar a la significación anterior de los valores nobles y dejar que éstos, en la historia, devengan en una nueva cultura basada en los valores nobles de la vida. Pero, primero, el hombre debe poder desenmascarar la falsa Verdad ${ }^{19}$.

18 «En verdad yo os digo, hay aquí algunos que no gustarán la muerte hasta que vean venir con poder el reino de Dios' (Mc. 9, 1). - Bien mentido, león...", Nietzsche (1997a: 87).

19 "Duros de cerviz y prudentes, como el asno, habéis sido siempre vosotros en cuanto abogados del pueblo.

Y más de un poderoso que quería marchar bien con el pueblo enganchó delante de sus corceles —un asnillo, un sabio famoso.

¡Y ahora yo quisiera, sabios famosos, que por fin arrojaseis totalmente de vosotros la piel de león!

¡La piel del animal de presa, de manchas multicolores, y las melenas del que investiga, busca, conquista!

¿Ay, para que yo aprendiera a creer en vuestra "veracidad" tendríais primero que hacer pedazos vuestra voluntad vencedora!", Nietzsche (1998b: 160). 
El hombre debe lograr quitar al borrego (que es el sacerdote) la piel de león que se ha puesto, piel de león debajo de la cual oculta su debilidad, su enfermedad, su vileza, su instinto de resentimiento y venganza ${ }^{20}$.

El superhombre debe poder llegar a extirpar el velo que cubre el mundo real que deviene, el hombre debe dejar de lado la Verdad, la mentira, y debe desenmascarar el engaño del mundo decadente, del nihilismo. Sólo así llegará a ser libre y podrá llegar a ser superhombre. Pero ese instinto creador pertenece al hombre, como también le pertenece el instinto de verdad. Por este motivo, el superhombre, el espíritu libre, sólo podrá ser aquel que llegue a darse cuenta que la Verdad es una mentira movida por la voluntad de poder, que la moral es un constructo movido por el instinto de resentimiento y venganza, que todo es un ir y venir de vida y muerte ${ }^{21}$.

El mundo, la verdad, el Ser... es el cambio, es la fuerza, es la contradicción, es la afirmación y la negación, es el no permanecer nunca como idéntico. Nietzsche afirma que el mundo es la experiencia particular, el "aquí y ahora», la espontaneidad de los sucesos que el concepto deja fuera; la verdad es el momento, la vida y la muerte, la expresión del mundo en nosotros. Como dice Nietzsche, y con ello concluyo,

“¿Y sabéis, en definitiva, qué es para mí el mundo?... ¿ ¿Tendré aún que mostrároslo en mi espejo?... Este mundo es prodigio de fuerza, sin principio, sin fin; una dimensión fija y fuerte como el bronce, que no se hace más grande ni más pequeña, que no se consume, sino que se transforma como un todo invariablemente grande; es una cosa sin gastos ni pérdidas, pero también sin incremento, encerrada dentro de la nada como en su límite; no es cosa que se concluya ni que se gaste, no es infinitamente extenso, sino que se encuentra inserto como fuerza, como juego de fuerzas y ondas de fuerza;

20 "Ya que no creemos que la verdad continua siendo verdad si se le arranca el velo; hemos vivido lo suficiente para no creer más en eso. Hoy se nos antoja decoroso no pretender verlo todo desnudo, presenciarlo todo, entenderlo y "saberlo" todo. “¿Es cierto que Dios está presente en todas partes?", preguntó a su madre una niña; "me parece indecente». - iTomen nota de esto los filosofos! Se debería respetar más el pudor con que la Naturaleza se ha ocultado tras enigmas e incertidumbres variopintas", Nietzsche (1988: 35 ).

21 "Todo lo que es simple, es meramente imaginario, y, claro está, no "verdadero». Lo que es verdadero, lo que es real, ni es uno ni se puede reducir a unidad", Nietzsche (1998c: 301). 
que es, al mismo tiempo, uno y múltiple; que se acumula aquí y al mismo tiempo disminuye alli: un mar de fuerzas normales que se agitan en sí mismas, que se transforman eternamente, que discurren eternamente; un mundo que cuenta con innumerables años de retorno, un flujo perpetuo de sus formas que se desarrollan desde la más simple a la más complicada; un mundo que desde lo más tranquilo, frío, rígido, pasa a lo que es más ardiente, salvaje, contradictorio, y que pasada la abundancia, torna a la sencillez, del juego de las contradicciones regresa al gusto de la armonía y se afirma a sí mismo aún en esta igualdad de sus caminos y de sus épocas, y se bendice a sí mismo como algo que debe tornar eternamente como un devenir que no conoce ni la saciedad ni el disgusto ni el cansancio. Este mundo mío dionisiaco que se crea siempre a sí mismo, que se destruye eternamente a sí mismo; este enigmático mundo de la doble voluptuosidad; este mi «más allá del bien y del mal", sin fin, a menos que no se descubra un fin en la felicidad del círculo; sin voluntad, a menos que un anillo no pruebe su buena voluntad, ¿queréis un nombre para ese mundo? ¿Queréis una solución para todos sus enigmas? ¿Queréis, en suma, una luz para vosotros, joh, desconocidos!, ¡oh, fuertes!, ¡oh, impávidos!, «hombres de medianoche?

¡Este nombre es el de "voluntad de poderío», y nada más!...”, Nietzsche (1998c: 554-5).

El mundo es vida y muerte, es uno y muchos, es un continuo ir y venir de fuerzas opuestas, de contradicciones, es un continuo retornar a lo mismo de aquello que nunca puede ser idéntico. Este mundo es una luz que se abre entre las tinieblas, pero a la vez es una sombra que tapa el sol como la luna cuando hay eclipse. El mundo es (todo) voluntad de poder, es (todo) un continuo choque de fuerzas intentando sobreponerse unas a las otras y un continuo permanecer por siempre ejerciendo su dominio, algo que sólo dura un instante, porque tras él, otra fuerza ocupa ese lugar de dominio. Sin embargo, el mundo es (todo) esta incesante lucha de fuerzas que quieren dominar sobre las demás y nunca permanecen pero, sin embargo, siempre vuelven a intentarlo.

\section{Bibliografía}

DeleuZe, Gilles; Nietzsche y la filosofia, traducción de Carmen Artal, Anagrama, Barcelona, 1971. 
Nietzsche, F; Ecce homo, traducción de A. Sánchez Pascual, Alianza, Madrid, 1971.

- El nacimiento de la tragedia, traducción de Andrés Sánchez Pascual, Alianza, Madrid, 1973. .

- La gaya ciencia, traducción de Charo Crego y Ger Groot, Akal, Barcelona, 1988.

- Sobre verdad y mentira en sentido extramoral, traducción de Luis Manuel Valdés y Teresa Orduña, Tecnos, Madrid, 1996.

- El anticristo, traducción de A. Sánchez Pascual, Alianza, Madrid, 1997a.

- Más allá del bien y del mal, traducción de Andrés Sánchez Pascual, Alianza, Madrid, $1997 \mathrm{~b}$.

- Creprisculo de los idolos, traducción de A. Sánchez Pascual, Alianza, Madrid, 1998a.

- Asi hablo Zaratustra, traducción de A. Sánchez Pascual, Alianza, Madrid, 1998b.

- La voluntad de poderío, traducción de Aníbal Froufe, Edaf, Madrid, 1998c.

- Cinco prólogos para cinco libros no escritos, traducción de Alejandro del Río Herrmann, Arena Libros, Madrid, 1999a.

- Aurora, traducción de Eduardo Knörr, Edaf, Madrid, 1999b.

- Sobre la utilidad y los perjuicios de la historia para la vida, traducción de Dionisio Garzón, Edaf, Madrid, 2000.

SUANCES y VILLAR; El irracionalismo, Vol. 2, Síntesis, 2000. 